\title{
Predictors of Clients' Satisfaction with Delivery of Animal Health Care Services in Periurban Ghana
}

\author{
Paa Kobina Turkson \\ Animal Science Department, School of Agriculture, University of Cape Coast, Cape Coast, Ghana \\ Correspondence should be addressed to Paa Kobina Turkson, kobbiecc@yahoo.com
}

Received 13 October 2010; Accepted 15 March 2011

Academic Editor: Nigel R. Perkins

Copyright () 2011 Paa Kobina Turkson. This is an open access article distributed under the Creative Commons Attribution License, which permits unrestricted use, distribution, and reproduction in any medium, provided the original work is properly cited.

\begin{abstract}
The study used logistic regression modelling to determine predictors of satisfaction with delivery of animal health care services for 889 clients (livestock and poultry keepers) in periurban Ghana. Of the 15 indicators tested as predictors of satisfaction in this study, 8 were included in the best fit model. These were accessibility, availability of services, service charge, effectiveness, efficiency, quality of services, meeting client needs, and getting help. Efficiency and effectiveness were perceived by the respondents to be synonymous, as were service quality and effectiveness, as suggested by ORs $>10$ when cross tabulated. Therefore, one or the other could be used in future studies but not both to avoid collinearity. The identified predictors could be targeted for improvement in quality of service delivery to livestock and poultry keepers in Ghana.
\end{abstract}

\section{Introduction}

Client satisfaction is often a measure of client's perception of quality because the highly satisfied client feels he/she has received a high-quality service, whereas the dissatisfied client is disappointed by the quality of service [1]. In medical literature where such studies are more common, client satisfaction is often referred to as patients' satisfaction $[2,3]$. Verbeek et al. [4] reported that patient satisfaction is best defined as patients' evaluation of (aspects of) a health care service based on the fulfilment of their expectations. Williams and colleagues [5] noted that the outcome of a patient's evaluation of services is based on 3 factors: a positive or negative experience; the perceived function of the service; the responsibility of the service for their experience. Vuori [6] observed that patient satisfaction is not just an indicator of health care but is a desired outcome of care, and therefore an essential part of its quality. It is expected that client evaluation would lead to improved quality of care as patient satisfaction is assessed to find out which services need improvement according to the patient's preference [4].

This paper presents findings of a client satisfaction survey and perceptions of quality of veterinary services in Ghana. Major findings have been published in Turkson [7].
This paper, a followup to the earlier publication, has the objective of determining what the predictors of satisfaction with veterinary services are and which model best explains client satisfaction from the indicators used in this study. This could help in improving the quality of services provided to livestock and poultry keepers in Ghana.

\section{Methods}

The details of the study area, sampling procedure, and survey instrument and administration have been provided in Turkson [7].

Briefly, urban/peri-urban locations in four regions of Ghana were chosen using purposive sampling technique. These were Kumasi Metropolitan Area and surrounding districts in the Ashanti Region; Accra and Tema Metropolitan Areas and Ga District in the Greater Accra Region; AwutuEfutu-Senya District in the Central Region; Shama-Ahanta East Metropolitan Area and surrounding districts in the Western Region.

2.1. Data Analysis. The responses to the closed questions were coded and stored using Microsoft Excel software. These were imported into Statistix software (version 3.5, Analytical 
Software Inc., St. Paul, MN, USA) and summarized using descriptive statistics.

For analysis, the respondents were classified into 2 groups based on the levels of satisfaction. Those who were either very dissatisfied, dissatisfied, or fairly dissatisfied with delivery of veterinary services to their farms were classified into dissatisfied group (making up 52.2\%, $n=889$ ), while those who were either satisfied or very satisfied were in the satisfied group (forming 47.8\%). Differences between those satisfied and those dissatisfied were tested for significance by the $\chi^{2}$ test at $\alpha=0.005$.

Modelling was used to determine the predictors of satisfaction with delivery of veterinary services from the indicators tested in this study. The best subsets regression model technique was adopted using Statistix software. The adjusted $R^{2}$ and Mallow's $C_{p}$ were the criteria for the model selection as suggested by Snedecor and Cochran [8] and Weisberg [9]. After the best model was selected, multiple logistic regression was used to generate a logit expression. Logistic regression was appropriate since the dependent variable consisted of "binary" data of "Yes" or "no." The dependent variable was satisfaction (with dummy variable 0 for the dissatisfied group and 1 for the satisfied group). The independent variables tested were responses to questions on effectiveness, efficiency, accessibility, service quality, equity, staff attitude, staff technical competence, service charge, drug costs, drug availability, vaccine availability, service availability, service affordability, client needs met, and ease of getting help. The definitions of these indicators are given by Turkson [7].

For effectiveness, efficiency, accessibility, service quality, equity, staff attitude, and staff technical competence, those who responded very poor, poor, fair, or no idea were put in poor group (with dummy variable 0 ), while those responding good or very good were classified as good group (with dummy variable 1). For service charge and drug costs, those who responded expensive, very expensive, or no idea were put in expensive group (with dummy variable 0 ), while those responding fair or reasonable were classified as reasonable Group (with dummy variable 1). For drug, vaccine, and service availability, those who responded unavailable or sometimes available were classified as unavailable group (with dummy variable 0), while those responding available or always available were classified as available group (with dummy variable 1). Those who said services were unaffordable, fairly affordable, or no idea were classified as unaffordable group (with dummy variable 0 ), while those who responded affordable were put in affordable group (with dummy variable 1). The respondents whose needs were poorly, sometimes, or fairly met were classified as unmet group (with dummy variable 0), while those whose needs were met or very much met were classified as met group (with dummy variable 1). For ease of getting help, those who responded "difficult" or "very difficult" were put in difficult group (with dummy variable 0), while those responding "easy" or "very easy" were classified as easy group (with dummy variable 1). The indicators chosen for the model were not forced, but each coefficient had to have a significant $P$ value at $95 \%$ confidence level.
To check for the collinearity of the parameters, pairs were cross tabulated using Statistix, while odds ratios (ORs) were calculated using EpiCalc 2000 version 1/02 [10]. ORs above 10 were interpreted as showing strong collinearity [7].

\section{Results}

Table 1 presents proportions for responses to questions on satisfaction with delivery of veterinary services in periurban Ghana. The differences between those satisfied and those not satisfied with quality of delivery of veterinary services in Ghana differed significantly $(P<0.05)$ with regard to accessibility, affordability, attitude of staff to clients, availability of service, service charge, availability of drugs, effectiveness, efficiency, equity, service quality, technical competence, availability of vaccines, meeting client needs, and getting help when in need. Generally, for each indicator the category denoting a positive inclination (e.g., good, affordable, available, reasonable, need met, and easy), the proportions for those satisfied were significantly higher than those for the dissatisfied respondents, except in the case of drug cost where the reverse was true.

The estimated logit for the best subsets regression model for satisfaction of clients with delivery of veterinary services in peri-urban Ghana was by the following expression:

$$
\begin{aligned}
\operatorname{Logit}(x)= & -2.99+0.38 a+1.00 b+0.58 c+0.59 d \\
+ & 0.60 e+0.65 f+0.87 g+0.42 h,
\end{aligned}
$$

where $x$ :Probability of Satisfaction $(0=$ dissatisfied, 1 = satisfied), $a$ :Accessibility ( 0 for poor, 1 for good), $b$ : Availability of services ( 0 for unavailable, 1 for available), $c$ : Service charge ( 0 for expensive, 1 for reasonable), $d$ : Client needs met ( 0 for unmet, 1 for met), e: Effectiveness ( 0 for poor, 1 for good), $f$ : Efficiency ( 0 for poor, 1 for good), $g$ : Getting help ( 0 for difficult, 1 for easy), and $h$ :Service quality (0 for poor, 1 for good).

Model (1) had a Marlow's $C_{p}$ of 9.0 and adjusted $R^{2}$ (the percentage of variance explained by the model) of $31.5 \%$.

The cross tabulations of indicators in the model that suggested strong collinearity were Efficiency $x$ effectiveness $\left(\mathrm{OR}=17 ; \chi^{2}=324.0 ; P<.00001\right)$ and Service quality $x$ effectiveness $\left(\mathrm{OR}=13 ; \chi^{2}=279.3 ; P<.00001\right)$. Taking these into consideration, 2 other models emerge and are expressed as

$$
\begin{aligned}
& \operatorname{Logit}(x)=-2.96+0.47 a+0.97 b+0.56 c \\
& +0.63 d+0.89 f+0.88 g+0.60 h, \\
& \text { Logit }(x)=-2.74+0.48 a+0.98 b+0.57 c \\
& +0.74 d+1.12 e+0.82 g .
\end{aligned}
$$

Table 2 presents the parameters for models (1)-(3). All the variables showed significant $P$ values at $\alpha=0.05$. 
TABLE 1: Indicators of quality of delivery of veterinary services in Ghana.

\begin{tabular}{|c|c|c|c|c|c|c|c|}
\hline \multirow{2}{*}{ Indicator } & & \multicolumn{2}{|c|}{ Satisfied \% } & \multicolumn{2}{|c|}{ Dissatisfied \% } & \multirow{2}{*}{$\chi^{2}$} & \multirow[t]{2}{*}{$P$} \\
\hline & & Number & $\%$ & Number & $\%$ & & \\
\hline \multirow{2}{*}{ Accessibility } & Poor & 193 & 35.5 & 351 & 64.5 & \multirow{2}{*}{85.39} & \multirow{2}{*}{$<.0001$} \\
\hline & Good & 232 & 67.2 & 113 & 32.8 & & \\
\hline \multirow{2}{*}{ Affordability } & Unaffordable & 186 & 37.3 & 312 & 62.7 & \multirow{2}{*}{49.62} & \multirow{2}{*}{$<.0001$} \\
\hline & Affordable & 239 & 61.1 & 153 & 38.9 & & \\
\hline \multirow{2}{*}{ Staff attitude } & Poor & 52 & 25.7 & 150 & 74.3 & \multirow{2}{*}{51.00} & \multirow{2}{*}{$<.0001$} \\
\hline & Good & 373 & 54.3 & 314 & 45.7 & & \\
\hline \multirow{2}{*}{ Service availability } & Unavailable & 108 & 26.0 & 308 & 74.0 & \multirow{2}{*}{149.5} & \multirow{2}{*}{$<.0001$} \\
\hline & Available & 317 & 67.0 & 156 & 33.0 & & \\
\hline \multirow{2}{*}{ Service charge } & Expensive & 117 & 33.8 & 229 & 66.2 & \multirow{2}{*}{44.44} & \multirow{2}{*}{$<.0001$} \\
\hline & Reasonable & 308 & 56.7 & 235 & 43.4 & & \\
\hline \multirow{2}{*}{ Drug availability } & Unavailable & 134 & 34.7 & 252 & 65.3 & \multirow{2}{*}{46.86} & \multirow{2}{*}{$<.0001$} \\
\hline & Available & 291 & 57.9 & 212 & 42.1 & & \\
\hline \multirow{2}{*}{ Drug cost } & Expensive & 311 & 48.1 & 335 & 51.9 & \multirow{2}{*}{0.11} & \multirow{2}{*}{.74} \\
\hline & Reasonable & 114 & 46.9 & 129 & 53.1 & & \\
\hline \multirow{2}{*}{ Effectiveness } & Poor & 126 & 29.2 & 306 & 70.8 & \multirow{2}{*}{117.0} & \multirow{2}{*}{$<.0001$} \\
\hline & Good & 299 & 65.4 & 158 & 34.6 & & \\
\hline Efficiency & Poor & 130 & 31.0 & 289 & 69.0 & 8944 & $<0001$ \\
\hline Limericy & Good & 295 & 62.8 & 175 & 37.2 & 07.74 & \\
\hline Equity & Poor & 318 & 44.6 & 395 & 55.4 & 14.84 & 0001 \\
\hline & Good & 107 & 60.8 & 69 & 39.2 & & \\
\hline Service quality & Poor & 106 & 27.5 & 272 & 72.5 & 111.9 & $<.0001$ \\
\hline Service quanty & Good & 319 & 63.3 & 185 & 36.7 & 111.9 & <.0001 \\
\hline Technical competence & Poor & 62 & 25.9 & 177 & 74.1 & 62.63 & $<.0001$ \\
\hline & Good & 363 & 55.8 & 287 & 44.2 & & \\
\hline Vaccine availability & Unavailable & 138 & 35.0 & 256 & 65.0 & 46.33 & $<0001$ \\
\hline & Available & 287 & 58.0 & 208 & 42.0 & & \\
\hline Client needs & Unmet & 122 & 28.2 & 311 & 71.8 & 130.38 & $<0001$ \\
\hline & Met & 303 & 66.4 & 153 & 33.6 & & \\
\hline Getting help & Difficult & 59 & 22.6 & 202 & 77.4 & 94.04 & $<.0001$ \\
\hline & Easy & 366 & 58.3 & 262 & 41.7 & & \\
\hline
\end{tabular}

TABLE 2: Regression parameters for 3 models of satisfaction of clients with delivery of animal health services in peri-urban Ghana.

\begin{tabular}{|c|c|c|c|c|c|c|c|c|c|}
\hline \multirow{2}{*}{ Predictor } & \multicolumn{3}{|c|}{ Model (1) } & \multicolumn{3}{|c|}{ Model (2) } & \multicolumn{3}{|c|}{ Model (3) } \\
\hline & Coefficient & $\begin{array}{l}\text { Wald test } \\
\text { statistic }\end{array}$ & $P$ value & Coefficient & $\begin{array}{l}\text { Wald test } \\
\text { statistic }\end{array}$ & $P$ value & Coefficient & $\begin{array}{l}\text { Wald test } \\
\text { statistic }\end{array}$ & $P$ value \\
\hline Constant & -2.99 & -12.70 & $<.001$ & -2.96 & -12.62 & $<.001$ & -2.74 & -12.37 & $<.001$ \\
\hline Accessibility & 0.38 & 2.02 & .043 & 0.47 & 2.58 & .010 & 0.48 & 2.61 & .009 \\
\hline Service availability & 1.00 & 5.46 & $<.001$ & 0.97 & 5.32 & $<.001$ & 0.98 & 5.44 & $<.001$ \\
\hline Service charge & 0.58 & 3.23 & .001 & 0.56 & 3.11 & .002 & 0.57 & 3.22 & .001 \\
\hline Client needs met & 0.59 & 3.26 & .001 & 0.63 & 3.53 & $<.001$ & 0.74 & 4.27 & $<.001$ \\
\hline Effectiveness & 0.60 & 2.70 & .007 & na & na & na & 1.12 & 6.30 & $<.001$ \\
\hline Efficiency & 0.65 & 3.20 & .001 & 0.89 & 4.87 & $<.001$ & na & na & na \\
\hline Getting help & 0.87 & 4.27 & $<.001$ & 0.88 & 4.35 & $<.001$ & 0.82 & 4.11 & $<.001$ \\
\hline Service quality & 0.42 & 2.05 & 0.040 & 0.60 & 3.19 & .001 & na & na & na \\
\hline
\end{tabular}

na $=$ not applicable. 


\section{Discussion}

The proportions of those satisfied were significantly higher and the responses more positive than those dissatisfied for all the indicators used to assess quality of services in peri-urban Ghana, except cost of drugs (Table 1). The indicators tested were able to differentiate those satisfied from those dissatisfied. Client satisfaction is a desired outcome of health care delivery and therefore an essential component of quality [6]. Therefore, if indicators that predict dissatisfaction are identified, they could be targeted to help improve service delivery.

Out of 15 indicators tested as predictors of satisfaction in this study, 8 were included in the best fit model. These were accessibility, availability of services, service charge, effectiveness, efficiency, quality of services, meeting client needs, and getting help. These ought to be tested further in other places. A number of these indicators (accessibility, service availability, charges, effectiveness, efficiency, and service quality) are said to influence quality of delivery of AHC systems and by extrapolation client satisfaction [11-17]. In human health services, the most powerful predictor for client satisfaction with government services was identified as provider behaviour especially respect and politeness, and these were more important than the technical competence of the provider [18]. Anecdotal information suggests a similar situation in veterinary services [17].

The results of the cross tabulations indicated that efficiency and effectiveness were perceived by the respondents to be identical or indistinguishable, as were service quality and effectiveness $(\mathrm{OR}>10)$. Effectiveness was defined in this study as how effective the veterinary services were in reducing mortality, disease, discomfort, and dissatisfaction, while efficiency was defined as how well the available resources were used to achieve desirable results. Quality of services was defined as the degree to which services met the client's expectations. It seems that the respondents were not able to sufficiently differentiate these. There is the need in future research to concentrate on using either indicator, rather than both to avoid collinearity. Also, either indicator could be used in prediction models as indicated in models (2) and (3).

This paper has for the first time provided predictors of client satisfaction with delivery of animal health care which could be used in improving quality of delivery of services to livestock and poultry keepers in Ghana and elsewhere.

\section{References}

[1] P. Moreau, "Clients' needs and expectations," Irish Veterinary Journal, vol. 60, no. 5, pp. 318-320, 2007.

[2] A. Donabedian, Explorations in Quality Assessment and Monitoring, Health Administration Press, Ann Arbor, Mich, USA, 1980.

[3] M. Morgan, "Patient satisfaction," in Profiting From Quality. Outcomes Strategies for Medical Practice, S. F. Isenberg and S. Gliklich, Eds., p. 84, Jossey Bass Publishers, San Francisco, Calif, USA, 1999.

[4] J. Verbeek, F. Van Dijk, K. Räsänen, H. Piirainen, E. Kankaanpää, and C. Hulshof, "Consumer satisfaction with occupational health services: should it be measured?" Occupational and Environmental Medicine, vol. 58, no. 4, pp. 272-278, 2001.
[5] B. Williams, J. Coyle, and D. Healy, "The meaning of patient satisfaction: an explanation of high reported levels," Social Science and Medicine, vol. 47, no. 9, pp. 1351-1359, 1998.

[6] H. Vuori, "Patient satisfaction-does it matter?" Quality Assurance in Health Care, vol. 3, no. 3, pp. 183-189, 1991.

[7] P. K. Turkson, "Client's satisfaction with delivery of animal health-care services in peri-urban Ghana," Preventive Veterinary Medicine, vol. 90, no. 3-4, pp. 153-159, 2009.

[8] G. W. Snedecor and W. G. Cochran, Statistical Methods, The Iowa State University Press, Ames, Iowa, USA, 7th edition, 1980.

[9] S. Weisberg, Applied Linear Regression, Wiley, New York, NY, USA, 2nd edition, 1985.

[10] J. Gilman and M. Myatt, Epicalc 2000, Brixton Books, 1998.

[11] J. E. Huhn, "Need and constraints to animal health and livestock services," in Proceedings of the Proceedings of International Workshop on Privatisation of Livestock Services, W. Richter, G. Freeland, and J. E. Huhn, Eds., Deutsche Stif-tung fur Internationale Entwicklung (DSE)/Zentralstelle fur Ernahrung und Landwirtschaft (ZEL), Feldafing, Germany, 1990.

[12] C. De Haan and S. Bekure, "Animal health services in sub-Saharan Africa: initial experiences with alternative appro-aches," World Bank Technical Paper 134, World Bank, Washington, DC, USA, 1991.

[13] Winrock International, Assessment of Animal Agriculture in Sub-Saharan Africa, Winrock International Institute for Agricultural development, Ark, USA, 1992.

[14] A. Mcleod and A. Wilsmore, "The delivery of animal health services to the poor: a review," in Investing in Animal Health Research to Alleviate Poverty, B. D. Perry, T. F. Randolph, J. J. McDermott, K. R. Sones, and P. K. Thornton, Eds., appendix 11, pp. 87-115, ILRI, Nairobi, 2002.

[15] P. Van Den Bossehe, E. Thys, R. Elyn, T. Marcotty, and S. Geerts, "The provision of animal health care to smallholders in Africa: an analytical approach," OIE Revue Scientifique et Technique, vol. 23, no. 3, pp. 851-861, 2004.

[16] P. K. Turkson, "Promotion of private veterinary practice in Ghana: perceptions of veterinarians and veterinary technicians," Tropical Animal Health and Production, vol. 36, no. 5, pp. 413-425, 2004.

[17] P. K. Turkson, "Perceptions of livestock owners of private veterinary practice in Ghana," Tropical Animal Health and Production, vol. 36, no. 5, pp. 427-434, 2004.

[18] J. M. Aldana, H. Piechulek, and A. Al-Sabir, "Client satisfaction and quality of health care in rural Bangladesh," Bulletin of the World Health Organization, vol. 79, no. 6, pp. 512-517, 2001. 

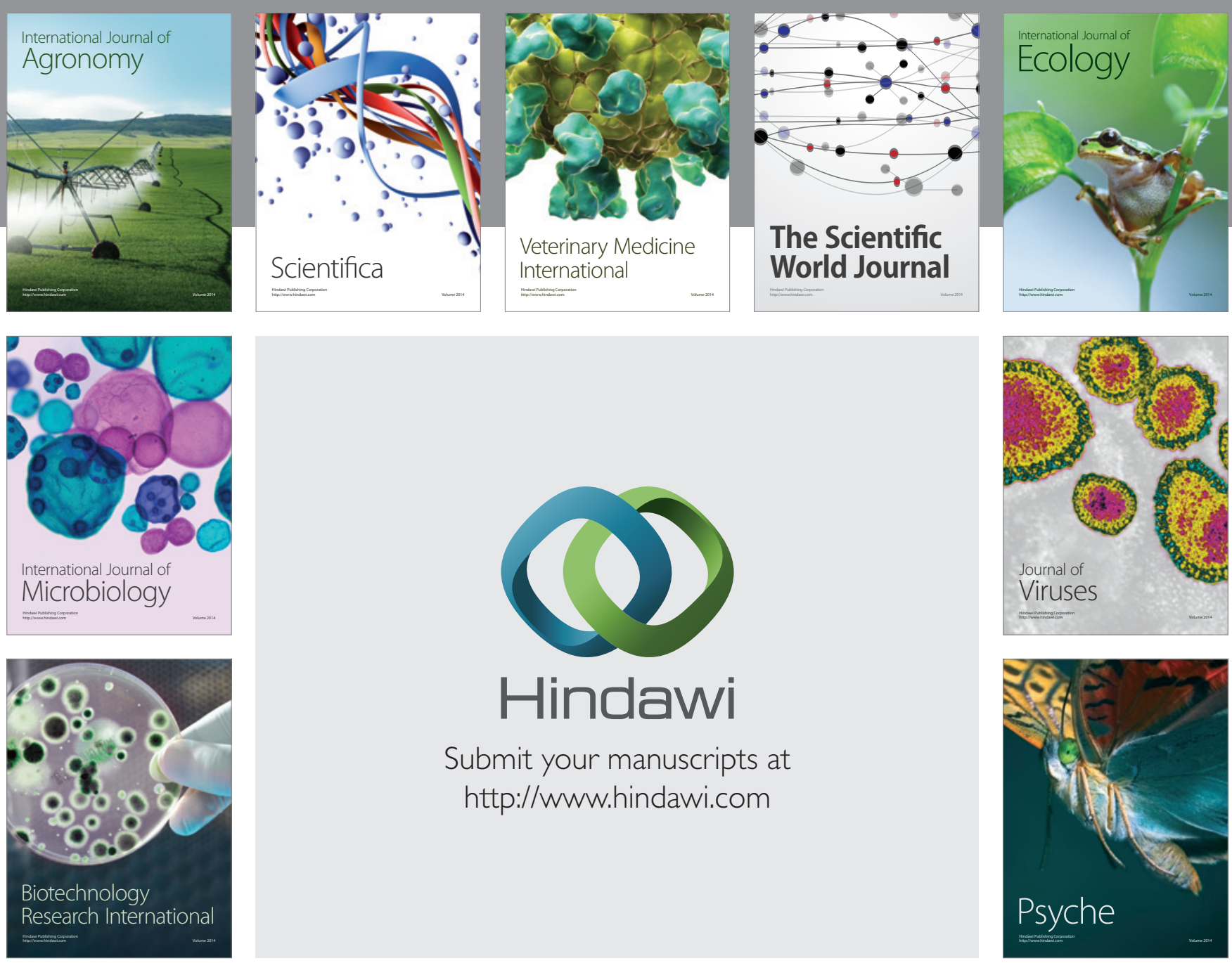

Submit your manuscripts at

http://www.hindawi.com
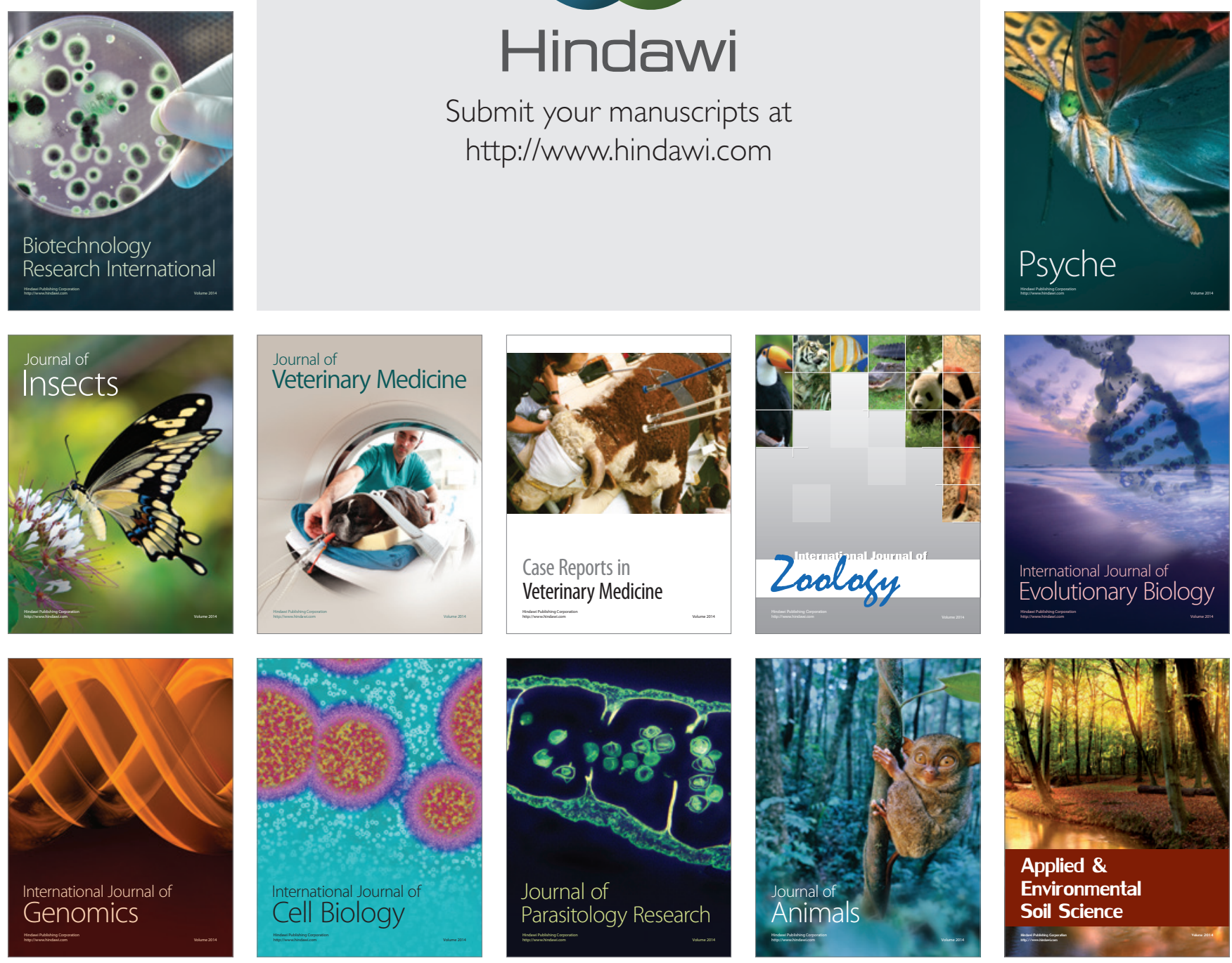